Pesq. Vet. Bras. 35(Supl.1):61-68, dezembro 2015 DOI: $10.1590 / \mathrm{S} 0100-736 \mathrm{X} 2015001300011$

\title{
Caracterização morfológica do trato gastrointestinal de frangos de corte da linhagem Cobb $500^{\circledR 1}$
}

\author{
Denise C. Sousa ${ }^{2}$, Nadja L.A. Oliveira ${ }^{2}$, Edna T. Santos ${ }^{3}$, Anderson Guzzi ${ }^{4}$, Leilane R.B. Dourado ${ }^{3}$ \\ e Guilherme J.B.C. Ferreira ${ }^{2 *}$
}

\begin{abstract}
Sousa D.C., Oliveira N.L.A., Santos E.T., Guzzi A., Dourado L.R.B. \& Ferreira G.J.B.C. 2015. [Morphological characterization of the gastrointestinal tract of Cobb $\mathbf{5 0 0}^{\circledR}$ broilers.] Caracterização morfológica do trato gastrointestinal de frangos de corte da linhagem Cobb 500 ${ }^{\circledR}$. Pesquisa Veterinária Brasileira 35(Supl.1):61-68. Curso de Medicina Veterinária, Universidade Federal do Piauí, Campus Universitário "Profa. Cinobelina Elvas", Rodovia BR-135 Km 3, Bairro Planalto Horizonte, Bom Jesus, PI 64900-000, Brazil. E-mail: guilherme.ferreira@ufpi.edu.br

This study aimed to describe the morphology of the digestive tract of broilers of the Cobb $500^{\circledR}$ lineage. The experiment was carried out in an experimental shed of the poultry sector of a Technical College in Bom Jesus county, Piauí, Brazil. The anatomical features of the digestive tract of eight 46-day-old broilers were evaluated with descriptive statistics and Pearson correlation analysis. Microscopic evaluation was performed by analysis of histological slides. It could be concluded that the Cobb $500^{\circledR}$ lineage demonstrated tissue stratigraphy of the digestive tube, consisting of four tunics, e.g. mucosa, submucosa, muscular and serosa, with exception of esophagus and crop which instead of a serous tunic has an adventitia tunic. In the esophagus exist mucous glands, but not in crop. In the mucosa of the proventriculus exist various mucous glands, which drain their secretions into secondary and primary ducts, and through an excretory duct into the lumen of the organ. The ventricle contains keratin in mucosa, and gastric glands in the lamina propria. In the ileum goblet cells are evident, but are also present in duodenum and jejunum. In the small and large intestine villi are evident, which become shorter and wider caudally to the digestive tract, with diffuse and nodular lymphoid tissue most evident in the large intestine.
\end{abstract}

INDEX TERMS: Gallus gallus domesticus, gastrointestinal tract, histology, stratigraphy.

RESUMO.- Caracterizou-se morfologicamente o tubo digestório de frangos de corte da linhagem Cobb $500^{\circledR}$. 0 experimento foi conduzido no setor de avicultura do Colégio Técnico de Bom Jesus, Piauí, em galpão experimental. Foram utilizados oito animais aos quarenta e seis dias de idade, e avaliou-se as características morfológicas macroscópica a partir da mensuração dos órgãos do tubo digestório, essas

\footnotetext{
${ }^{1}$ Recebido em 5 de dezembro de 2014.

Aceito para publicação em 21 de dezembro de 2015.

${ }^{2}$ Curso de Medicina Veterinária do Campus "Prof. Cinobelina Elvas", Universidade Federal do Piauí (UFPI), Rodovia BR-135 Km 3 s/n, Planalto Horizonte, Bom Jesus, PI 64900-000, Brasil. *Autor para correspondência: guilherme.ferreira@ufpi.edu.br

${ }^{3}$ Curso de Zootecnia do Campus "Prof. Cinobelina Elvas", UFPI, Rodovia BR-135 Km 3 s/n, Planalto Horizonte, Bom Jesus, PI 64900-000, Brasil.

${ }^{4}$ Curso de Ciências Biológicas, Departamento de Ciências do Mar, Campus 'Ministro Reis Velloso", UFPI, Av. São Sebastião, 2819, Parnaíba, PI 64202-020, Brasil.
}

foram avaliadas através de análise estatística descritiva e análise correlação de Pearson. A avaliação microscópica foi realizada pela análise das lâminas histológicas. Conclui-se que a linhagem $\mathrm{Cobb} 500^{\circledR}$ demonstrou estratigrafia tecidual do tubo digestório, composta por quatro túnicas: mucosa, submucosa, muscular e serosa, com exceção do esôfago e inglúvio que ao invés de possuir túnica serosa possui a adventícia. No esôfago há presença de glândulas mucosas, e no inglúvio são ausentes. 0 proventrículo é estruturado por várias glândulas mucosas localizadas na túnica mucosa, que drenam suas secreções em ductos secundários e primários e ao um ducto excretor em direção ao lúmen do órgão. 0 ventrículo possui um conteúdo queratinóide na túnica mucosa, glândulas gástricas na lâmina própria. No intestino delgado é mais visível a presença de células caliciformes no íleo, porém também estão presentes no duodeno e no jejuno. Em ambos os intestinos delgado e grosso é visível à presença de vilos, que se tornam mais curtos e lar- 
gos caudalmente ao tubo digestório, apresentam em seus segmentos a presença de tecido linfático difuso e nodular, sendo estes mais evidenciados no intestino grosso.

TERMOS DE INDEXAÇÃO: Gallus gallus domesticus, trato gastrointestinal, histologia, estratigrafia.

\section{INTRODUÇÃO}

São três os principais fatores que interferem no desempenho de frangos de corte: idade ao abate, sexo e genética (Bilgili et al. 1992). Dentre as linhagens mais utilizadas na atividade avícola de corte encontra-se a linhagem Coob $500^{\circledR}$, essa tem demonstrado lugar de destaque com altos índices de rentabilidade. 0 desenvolvimento dessa linhagem surgiu pela necessidade de um produto com conformação superior e alta conversão alimentar, que através do cruzamento de fêmeas White Rock e machos Vantress iniciou-se a produção de aves da linhagem Cobb $500^{\circledR}$, cujos frangos após um rigoroso processo de seleção adquiriram características como rápido crescimento, eficiência alimentar, baixa mortalidade e alto rendimento de carcaça (Cobb Vantress Brasil 2002), tais características são imprimidas pelo melhoramento genético.

Devido aos cruzamentos e seleções as aves podem sofrer variações anatômicas (Didio 1986), apesar da sua morfologia apresentar poucas variações dentro da classe, quando comparada a outras ordens de peixes, anfíbios, répteis e mamíferos (King 1986). Considerando a busca por animais que desenvolvam um bom desempenho zootécnico, essas variações podem estar ocorrendo sem que sejam percebidas, devido à deficiência de estudos relacionados as características morfológicas desses animais, principalmente acerca da morfologia do trato digestório dessas aves, tendo em vista que esse é o local responsável pelo metabolismo dos nutrientes ingeridos a partir da dieta.

As pesquisas relacionadas aos aspectos morfológicos do sistema digestório das aves, demonstram papel relevante no desenvolvimento da avicultura, pois se tornam indispensáveis na compreensão do funcionamento do processo de digestão, principalmente em frangos de corte, para informar o quanto os diferentes ingredientes contidos na dieta desses animais podem influenciar no desempenho das funções desse sistema e nas condições de sanidade dessas aves. 0 prévio conhecimento da morfologia desse sistema facilita o entendimento dos mecanismos de ação envolvidos com o aproveitamento dos nutrientes podendo resultar em melhor desenvolvimento do setor avícola.

Neste contexto, o conhecimento das características morfológicas das diferentes linhagens de frango de corte pode contribuir para instituir melhores estratégias de manejo alimentar e sanidade avícola. Diante do exposto, objetivou-se descrever as características morfológicas do tubo digestório da linhagem de frango de corte Cobb $500^{\circledR}$.

\section{MATERIAL E MÉTODOS}

O experimento foi conduzido no setor de avicultura do Colégio Técnico de Bom Jesus, da Universidade Federal do Piauí, em Bom Jesus, Piauí, em galpão experimental. Foram utilizados oito animais, machos, da linhagem Cobb $500^{\circledR}$, do sexo macho.
O programa nutricional utilizado durante o experimento foi composto por cinco rações, destinadas às diferentes fases de criação das aves: pré-inicial de um a sete dias, inicial de oito a vinte e um dias, crescimento de vinte e dois a trinta e cinco dias, final de trinta e seis a quarenta e dois dias e terminação de quarenta e três a quarenta e seis dias.

As rações foram formuladas para atender as exigências nutricionais de frangos machos de desempenho regular, conforme os níveis nutricionais recomendados por Rostagno et. al. (2011).

Os animais foram coletados aos 46 dias de idade, com uma média de peso de $2733,75 \pm 214,37 \mathrm{~g}$, e posteriormente foi realizada a eutanásia conforme resolução 1000/2012 do Conselho Federal de Medicina Veterinária (CFMV 2012).

Inicialmente, realizou-se a contenção manual das aves, seguida de limpeza da face medial da asa e anti-sepsia; anestesia local na região descrita, com um cordão anestésico de lidocaína sem vasoconstritor na dose de $5 \mathrm{mg} / \mathrm{kg}$ por via subcutânea (Viana 2007).

Após anestesia local, foi feita a dissecação da veia radial e isolamento da mesma com auxílio de fios de sutura e canulação do vaso, seguido da injeção de heparina na dose de 150UI/Kg PV (Viana 2007), depois de transcorridos dois minutos, injetou-se tiopental diluído em água destilada a $25 \mathrm{mg} / \mathrm{ml}$ (Viana 2007), pela mesma cânula, na dose de $15 \mathrm{mg} / \mathrm{kg}$ PV, após eutanásia foi feita a perfusão de formaldeído tamponado a $10 \%$ por gravidade (Chen 2010), durante 6 horas, seguido de imersão em cuba contendo mesma solução, por no mínimo 72 horas.

Após este período os animais foram dissecados com auxílio de pinças anatômicas, bisturi, lupa de Pala, que proporcionou melhor visualização dos órgãos. Os dados da mensuração macroscópica dos órgãos foram obtidos com auxílio de paquímetro digital e fita métrica e anotados em fichas e logo após foram compilados em quadros elaboradas no programa Microsoft Excel 2010. Ao término das mensurações, o tubo digestório foi segmentado a partir da realização de cortes transversais, em fragmentos de aproximadamente $1 \mathrm{~cm}$. Os segmentos do trato grastrointestinal foram lavados com solução fisiológica e acondicionados em formalina a 10\%. (Xia et al. 2004, Hu et al. 2012).

Em sequência a coleta de todos os fragmentos, estes foram submetidos ao processamento histológico padrão com inclusão em Paraplast ${ }^{\circledR}$ (Paraplast Embedding Media - Paraplast Plus ${ }^{\circledR}$ ) e posterior secção dos blocos na espessura de $4 \mu \mathrm{m}$ em micrótomo rotativo semiautomático, após a seção os cortes foram corados com hematoxilina e eosina (Xia et al. 2004, Hu et al. 2012).

Foram realizados dois estudos acerca da morfologia do tubo digestório dessas aves: o macroscópico e o microscópico.

No estudo macroscópico foram avaliados: peso vivo do animal, comprimento total e diâmetro do esôfago (mensurado da laringe até sua junção com o proventrículo), inglúvio, proventrículo, ventrículo, intestino delgado (duodeno: a partir do piloro até a porção distal da alça duodenal; jejuno: a partir da alça duodenal distal até a junção ileocecal; e o íleo: da porção anterior dos cecos até a junção ileocecal) e intestino grosso (cecos: das suas bases até o ápice e o colón: da junção ileocecal até porção anterior da coacla), regiões definidas segundo Getty (1986). O diâmetro dos órgãos foi aferido nas porções proximal, média e distal.

A avaliação histológica foi realizada pela análise dos cortes em microscópio biológico. 0 estudo microscópico avaliou a composição estrutural dos tecidos de cada órgão, as fotomicrografias foram registradas por meio de uma ocular digital de dois megapixels (DEM200 Digital Eyepiece for Microscope - Scopetek ${ }^{\circledR}$ ) acoplada a um microscópio biológico trinocular (Nova ${ }^{\circledR}$ ), associada ao software de captura Minisee ${ }^{\circledR}$.

As mensurações de comprimento e diâmetro foram avaliadas através de análise estatística descritiva e análise correlação de Pearson, realizado com o software Bioestat $5.3^{\circledR}$. O coeficiente de 
correlação de Pearson mede a associação linear entre variáveis quantitativas e o seu valor varia entre -1 e 1, quanto mais próximos aos valores extremos, há maior associação linear. A correlação é estatisticamente significativa, quando os valores de significância se encontram inferiores aos valores de referência $(0,05$, 0,01 e 0,001), porém quando as significâncias são superiores aos valores de referência, a correlação não é estatisticamente significativa.

Todo o procedimento utilizado na condução do experimento foi submetido ao Comitê de Ética em Experimentação Animal, da Universidade Federal do Piauí e aprovado sob parecer no 89/12.

\section{RESULTADOS}

$\mathrm{Na}$ análise macroscópica do esôfago este apresentou comprimento médio de $15,50 \pm 1,51 \mathrm{~cm}$, quanto ao diâmetro desse órgão, foram mensurados os dois segmentos cervical e torácico. No segmento cervical, foram mensuradas as porções cranial, médio e caudal, obtendo-se as seguintes médias respectivamente: $6,69 \pm 1,47 \mathrm{~mm}, 5,68 \pm 0,81 \mathrm{~mm}$ e $5,68 \pm 0,93 \mathrm{~mm}$. No segmento torácico, apresentaram as seguintes médias das porções cranial, médio e caudal, respectivamente: $5,13 \pm 0,892 \mathrm{~mm}, 4,44 \pm 1,60 \mathrm{~mm}$ e $6,04 \pm 1,58 \mathrm{~mm}$. 0 inglúvio exibiu comprimento médio de $4,88 \pm 0,99 \mathrm{~cm}$ e diâmetro médio de $30,38 \pm 5,42 \mathrm{~mm}$. 0 proventrículo apresentou comprimento médio de $5,38 \pm 0,74 \mathrm{~cm}$ e os diâmetros médios foram mensurados das porções cranial, média e caudal respectivamente: $10,46 \pm 2,14 \mathrm{~mm}, 15,73 \pm 1,76 \mathrm{~mm}$ e $11,55 \pm 2,82 \mathrm{~mm}$. O ventrículo apresentou comprimento médio de 8,50 $\pm 1,20 \mathrm{~cm}$ e diâmetro médio de $13,64 \pm 1,89 \mathrm{~mm}$.

0 intestino delgado é formado por três segmentos: duodeno, jejuno e íleo. Macroscopicamente esses órgãos exibiram os seguintes comprimentos médios, duodeno $32,38 \pm 4,24 \mathrm{~cm}$; jejuno $110,88 \pm 9,39 \mathrm{~cm}$; e íleo $20,25 \pm 3,20 \mathrm{~cm}$, sendo o íleo mensurado a partir da prega íleocecal direita, os diâmetros foram mensurados de acordo com os diferentes segmentos de cada órgão do intestino delgado.

0 diâmetro do duodeno foi avaliado em seus três distintos segmentos: duodeno descendente, flexura duodenal e duodeno ascendente, estes delimitados pela presença do pâncreas. Cada segmento foi mensurado em suas porções cranial, médio e caudal exceto para a flexura onde realizou-se apenas uma mensuração. Este segmento intestinal apresentou nas suas porções as seguintes médias: duodeno descendente, porção cranial $6,62 \pm 1,14 \mathrm{~mm}$, porção média $7,00 \pm 1,61 \mathrm{~mm}$ e na porção caudal $7,05 \pm 1,60 \mathrm{~mm}$. A flexura

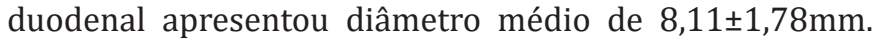
No duodeno ascendente obteve-se os diâmetros a seguir: cranial $7,23 \pm 1,70 \mathrm{~mm}$, médio $7,69 \pm 1,34 \mathrm{~mm}$ e caudal $7,31 \pm 2,06 \mathrm{~mm}$.

0 jejuno exibiu diâmetro médio no segmento cranial

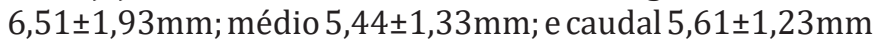

Quadro 1. Estatística descritiva dos diâmetros (em $\mathrm{mm}$ ) dos órgãos do tubo gastrintestinal de frangos da linhagem Cobb $^{\circledR}$

\begin{tabular}{|c|c|c|c|c|c|c|c|c|}
\hline & & Mínimo & Máximo & $\begin{array}{l}\text { Amplitude } \\
\text { total }\end{array}$ & $\begin{array}{c}\text { Média } \\
\text { aritmética }\end{array}$ & Variância & $\begin{array}{l}\text { Desvio } \\
\text { padrão }\end{array}$ & $\begin{array}{l}\text { Coeficiente } \\
\text { de variação }\end{array}$ \\
\hline \multirow[t]{3}{*}{ Esôfago Cervical } & CR & 5,70 & 10,25 & 4,55 & 6,6938 & 2,1653 & 1,4715 & $21,98 \%$ \\
\hline & M & 5,05 & 7,55 & 2,5 & 5,675 & 0,6571 & 0,8106 & $14,28 \%$ \\
\hline & CD & 3,90 & 7,05 & 3,15 & 5,675 & 0,8621 & 0,9285 & $16,36 \%$ \\
\hline \multirow[t]{3}{*}{ Esôfago Torácico } & CR & 3,75 & 6,9 & 3,15 & 5,1313 & 0,7957 & 0,892 & $17,38 \%$ \\
\hline & M & 1,75 & 7,65 & 5,9 & 4,4375 & 2,5684 & 1,6026 & $36,12 \%$ \\
\hline & CD & 3,50 & 8,4 & 4,9 & 6,0375 & 2,4848 & 1,5763 & $26,11 \%$ \\
\hline Inglúvio & & 25,70 & 40,35 & 14,65 & 30,3813 & 29,4085 & 5,423 & $17,85 \%$ \\
\hline \multirow[t]{3}{*}{ Pró-ventrículo } & CR & 6,85 & 13,05 & 6,2 & 10,4563 & 4,5732 & 2,1385 & $20,45 \%$ \\
\hline & M & 12,90 & 18,05 & 5,15 & 15,725 & 3,1057 & 1,7623 & $11,21 \%$ \\
\hline & CD & 5,05 & 13,85 & 8,8 & 11,55 & 7,9421 & 2,8182 & $24,40 \%$ \\
\hline Ventrículo & & 9,53 & 15,825 & 6,3 & 13,6375 & 3,5568 & 1,8859 & $13,83 \%$ \\
\hline \multirow[t]{3}{*}{ Duodeno descendente } & CR & 4,65 & 8,15 & 3,5 & 6,6188 & 1,2892 & 1,1354 & $17,16 \%$ \\
\hline & M & 4,15 & 9,4 & 5,25 & 7 & 2,5771 & 1,6053 & $22,93 \%$ \\
\hline & CD & 3,90 & 9,05 & 5,15 & 7,05 & 2,5686 & 1,6027 & $22,73 \%$ \\
\hline Flexura & & 4,65 & 10,9 & 6,25 & 8,1125 & 3,172 & 1,781 & $21,95 \%$ \\
\hline \multirow[t]{3}{*}{ Duodeno ascendente } & CR & 4,05 & 9,25 & 5,2 & 7,225 & 2,9043 & 1,7042 & $23,59 \%$ \\
\hline & M & 4,95 & 8,9 & 3,95 & 7,6938 & 1,7846 & 1,3359 & $17,36 \%$ \\
\hline & CD & 4,20 & 10,3 & 6,1 & 7,3063 & 4,231 & 2,0569 & $28,15 \%$ \\
\hline \multirow[t]{3}{*}{ Jejuno } & CR & 2,85 & 9,05 & 6,2 & 6,5125 & 3,7091 & 1,9259 & $29,57 \%$ \\
\hline & M & 2,55 & 6,85 & 4,3 & 5,4438 & 1,7582 & 1,326 & $24,36 \%$ \\
\hline & CD & 3,80 & 7,10 & 3,3 & 5,6125 & 1,502 & 1,2255 & $21,84 \%$ \\
\hline \multirow[t]{3}{*}{ Ílio } & CR & 4,25 & 6,30 & 2,05 & 5,2438 & 0,7132 & 0,8445 & $16,10 \%$ \\
\hline & M & 3,80 & 8,90 & 5,1 & 5,275 & 2,7343 & 1,6536 & $31,35 \%$ \\
\hline & $\mathrm{CD}$ & 3,55 & 6,30 & 2,75 & 4,425 & 0,8093 & 0,8996 & $20,33 \%$ \\
\hline \multirow[t]{3}{*}{ Ceco Direito } & BASE & 2,65 & 5,80 & 3,15 & 4,4438 & 1,531 & 1,2373 & $27,84 \%$ \\
\hline & CORPO & 1,95 & 7,55 & 5,6 & 4,1688 & 2,7328 & 1,6531 & $39,66 \%$ \\
\hline & ÁPICE & 2,20 & 7,90 & 5,7 & 5,4375 & 3,1341 & 1,7703 & $32,56 \%$ \\
\hline \multirow[t]{3}{*}{ Ceco Esquerdo } & BASE & 2,20 & 5,80 & 3,60 & 4,5188 & 1,3557 & 1,1643 & $25,77 \%$ \\
\hline & CORPO & 2,65 & 10,75 & 8,10 & 4,95 & 6,2593 & 2,5019 & $50,54 \%$ \\
\hline & ÁPICE & 2,80 & 8,20 & 5,40 & 5,6625 & 2,5548 & 1,5984 & $28,23 \%$ \\
\hline \multirow[t]{3}{*}{ Cólon } & $\mathrm{CR}$ & 4,30 & 8,35 & 4,05 & 6,6875 & 1,7248 & 1,3133 & $19,64 \%$ \\
\hline & $\mathrm{M}$ & 4,75 & 7,60 & 2,85 & 6,1875 & 0,8355 & 0,9141 & $14,77 \%$ \\
\hline & CD & 4,10 & 8,20 & 4,10 & 6,4313 & 1,6892 & 1,2997 & $20,21 \%$ \\
\hline
\end{tabular}

$\mathrm{CR}=$ cranial, $\mathrm{M}=$ médio, $\mathrm{CD}=$ caudal. 
e no íleo diâmetro médio mensurado no segmento cranial $5,24 \pm 0,84 \mathrm{~mm}$, na porção média $5,28 \pm 1,65 \mathrm{~mm}$ e no segmento caudal $4,43 \pm 0,89 \mathrm{~mm}$.

No intestino grosso analisou-se a caracterização morfológica dos dois cecos (direito e esquerdo) e do colón. Macroscopicamente, os cecos direito e esquerdo apresentaram os seguintes comprimentos médios, respectivamente: $20,75 \pm 1,17 \mathrm{~cm}$ e $21,38 \pm 1,92 \mathrm{~cm}$. Foram obtidos os diâmetros dos cecos direito nas regiões da base, corpo e ápice e demonstraram as seguintes médias: $4,44 \pm 1,24 \mathrm{~mm}$; $4,17 \pm 1,65 \mathrm{~mm}$; e $5,44 \pm 1,77 \mathrm{~mm}$, respectivamente e o ceco esquerdo os diâmetros as médias foram: 4,52 $\pm 1,16 \mathrm{~mm}$; $4,95 \pm 2,50 \mathrm{~mm}$; e $5,66 \pm 1,59 \mathrm{~mm}$, correspondente à ordem das regiões citadas anteriormente. Quanto ao cólon, este exibiu comprimento médio de $7,88 \pm 0,99 \mathrm{~cm}$ e diâmetro médio nas porções cranial $6,69 \pm 1,31 \mathrm{~mm}$, média $6,19 \pm 0,91 \mathrm{~mm}$ e caudal $6,43 \pm 1,29 \mathrm{~mm}$.

No Quadro 1 descreve-se a estatística descritiva dos diâmetros dos órgãos do tubo digestório dos animais estudados e no Quadro 2 está apresentada a estatística descritiva referente ao comprimento dos mesmos.

A análise de correlação de Pearson, esta apresentada em forma da matriz (Quadro 3), as variáveis que apresentaram associação linear foram entre o comprimento do esôfago e do proventrículo $(\mathrm{r}=0,83 ; \mathrm{P}<0,05)$, o comprimento do esôfago e do ventrículo $(\mathrm{r}=0,71 ; \mathrm{P}<0,05)$, o peso vivo e o comprimento do duodeno $(\mathrm{r}=0,76$; $\mathrm{P}<0,05)$ e o tamanho do ceco esquerdo e o ceco direito $(\mathrm{r}=0,75 ; \mathrm{P}<0,05)$, porém as variáveis que exibiram altas correlações foram as seguintes: tamanho

Quadro 2. Estatística descritiva do peso de frangos da linhagem $\operatorname{Cobb}^{\circledR}$ e comprimento dos órgãos do tubo gastrintestinal

\begin{tabular}{lrrrrrr}
\hline & Mínimo & Máximo & $\begin{array}{c}\text { Amplitude } \\
\text { total }\end{array}$ & $\begin{array}{r}\text { Média } \\
\text { aritmética }\end{array}$ & $\begin{array}{r}\text { Desvio } \\
\text { padrão }\end{array}$ & $\begin{array}{c}\text { Coeficiente } \\
\text { de variação }\end{array}$ \\
\hline Peso (g) & 2416,00 & 3038,00 & 622,00 & 2733,75 & 214,37 & $7,84 \%$ \\
Esôfago (cm) & 14,00 & 19,00 & 5,00 & 15,50 & 1,51 & $9,75 \%$ \\
Inglúvio (cm) & 4,00 & 6,00 & 2,00 & 4,88 & 0,99 & $20,33 \%$ \\
Pró-ventrículo (cm) & 5,00 & 7,00 & 2,00 & 5,38 & 0,74 & $13,84 \%$ \\
Ventrículo (cm) & 7,00 & 11,00 & 4,00 & 8,50 & 1,20 & $14,06 \%$ \\
Duodeno (cm) & 27,00 & 39,00 & 12,00 & 32,38 & 4,24 & $13,10 \%$ \\
Jejuno (cm) & 101,00 & 124,00 & 23,00 & 110,88 & 9,39 & $8,47 \%$ \\
Íleo (cm) & 16,00 & 25,00 & 9,00 & 20,25 & 3,20 & $15,78 \%$ \\
Ceco Esquerdo (cm) & 19,00 & 24,00 & 5,00 & 21,38 & 1,92 & $8,99 \%$ \\
Ceco Direito (cm) & 19,00 & 22,00 & 3,00 & 20,75 & 1,17 & $5,61 \%$ \\
Cólon (cm) & 6,00 & 9,00 & 3,00 & 7,88 & 0,99 & $12,58 \%$
\end{tabular}

do ceco direito e o peso vivo ( $\mathrm{r}=0,84 ; \mathrm{P}<0,01)$, o comprimento do proventrículo e do ventrículo $(\mathrm{r}=0,88 ; \mathrm{P}<0,01)$ e o tamanho do duodeno e do ceco direito $(\mathrm{r}=0,89 ; \mathrm{P}<0,01)$.

Ao realizar a análise histológica foi possível visualizar a estratigrafia dos diferentes órgãos que constituem o tubo

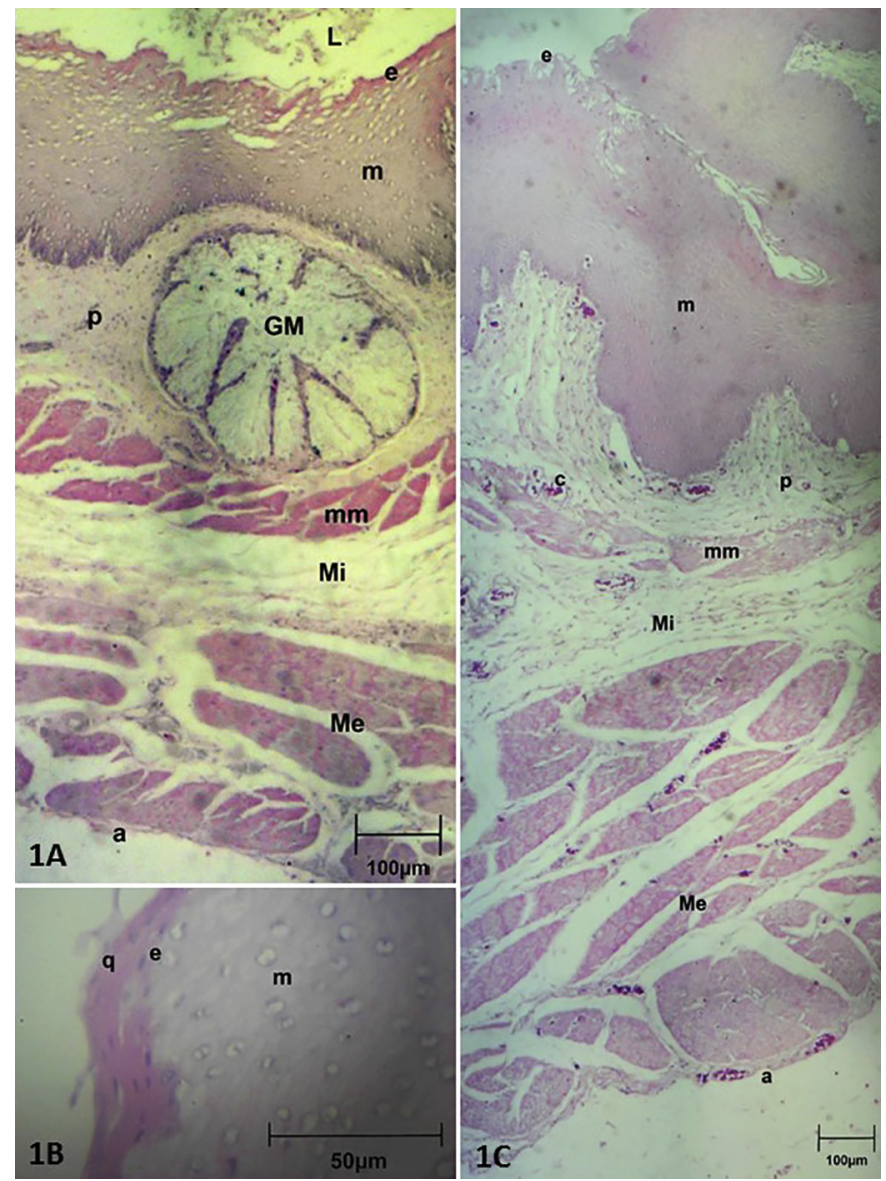

Fig.1. (1A e 1B) Esôfago de frangos da linhagem Cobb e (1C) inglúvio. (1A) Lúmen (L), Epitélio (e), Mucosa (m), Lâmina própria (p), Glândula mucosa (GM), Muscular da mucosa (mm). Muscular interna (Mi), Muscular externa (Me), Adventícia (a). HE, obj.4x. (1B) Mucosa (m) do esôfago com epitélio estratificado queratinizado (e), Queratinização (q). HE, obj.20x. (1C) Epitélio (e), Mucosa (m), Lâmina própria (p), Capilar (c), Muscular da mucosa (mm), Muscular interna (Mi), Muscular externa (Me), Adventícia (a). HE, obj.4x.

Quadro 3. Coeficientes de correlação de Person entre as variáveis: peso e órgãos do tubo digestório de frangos de corte da linhagem $\operatorname{Cobb}^{\circledR}$ aos 46 dias de idade

\begin{tabular}{lcccccccccc}
\hline & $\begin{array}{c}\text { PV } \\
(\mathrm{kg})\end{array}$ & \multicolumn{2}{c}{ Esôfago Inglúvio Proventr. Ventrículo Duodeno } \\
& $(\mathrm{cm})$ & $(\mathrm{cm})$ & $(\mathrm{cm})$ & $(\mathrm{cm})$ & $(\mathrm{cm})$ & $\begin{array}{c}\text { Jejuno } \\
(\mathrm{cm})\end{array}$ & $\begin{array}{c}\text { Íleo } \\
(\mathrm{cm})\end{array}$ & $\begin{array}{c}\text { Ceco E Ceco D } \\
(\mathrm{cm})\end{array}$ & $(\mathrm{cm})$ \\
\hline Esôfago & 0,43 & - & - & - & - & - & - & - & - & - \\
Inglúvio & 0,60 & 0,43 & - & - & - & - & - & - & - & - \\
Provent. & 0,49 & $0,83^{*}$ & 0,65 & - & - & - & - & - & - & - \\
Ventrículo & 0,63 & $0,71^{*}$ & 0,66 & $0,88^{* *}$ & - & - & - & - & - & - \\
Duodeno & $0,76^{*}$ & 0,01 & 0,35 & 0,36 & 0,47 & - & - & - & - & - \\
Jejuno & 0,07 & 0,51 & 0,26 & 0,33 & 0,39 & $-0,33$ & - & - & - & - \\
Íleo & $-0,44$ & $-0,21$ & $-0,48$ & 0,02 & $-0,04$ & 0,07 & 0,05 & - & - & - \\
Ceco E & 0,31 & $-0,27$ & $-0,05$ & 0,09 & 0,22 & 0,70 & $-0,62$ & 0,19 & & - \\
Ceco D & $0,84^{* *}$ & 0,24 & 0,34 & 0,45 & 0,62 & $0,89^{* *}$ & $-0,28$ & 0,13 & $0,75^{*}$ & - \\
Cólon & $-0,38$ & 0,14 & $-0,30$ & 0,27 & $-0,06$ & $-0,02$ & $-0,45$ & 0,46 & 0,25 & $-0,03$
\end{tabular}

${ }^{*} \mathrm{p}<0,05 ;{ }^{* *} \mathrm{p}<0,01 . \mathrm{PV}=$ peso vivo, Ceco $\mathrm{E}=$ ceco esquerdo, Ceco $\mathrm{D}=$ ceco direito, Provent. = proventrículo. 
digestório de frangos de corte da linhagem Cobb $500^{\circledR}$ : esôfago, inglúvio, proventrículo, ventrículo, intestino delgado e intestino grosso, em suas porções proximal, médio e distal.

0 esôfago é um órgão tubular que se estende da faringe até o esôfago. Esse órgão esta organizado estruturalmente em quatro túnicas, do lúmen em direção a sua parede externa: mucosa, submucosa, muscular e adventícia. A mucosa é formada por tecido epitelial pavimentoso estratificado queratinizado (Fig.1B), pela lâmina própria e essa composta por tecido epitelial contendo tecido linfático difuso. A muscular da mucosa é formada por tecido ondulado (formando dobras) de músculo liso orientando em sentido longitudinal em direção ao lúmen. A submucosa é formada por tecido conjuntivo frouxo, tecido linfático nodular e difuso e estão presentes glândulas mucosas túbulo alveolares ramificadas (Fig.1A).

O inglúvio é um divertículo esofágico o qual armazena alimento, difere estruturalmente do esôfago por não ser comum a visualização das glândulas mucosas (Fig.1C), porém em uma amostra foi possível visualizar a presença destas.

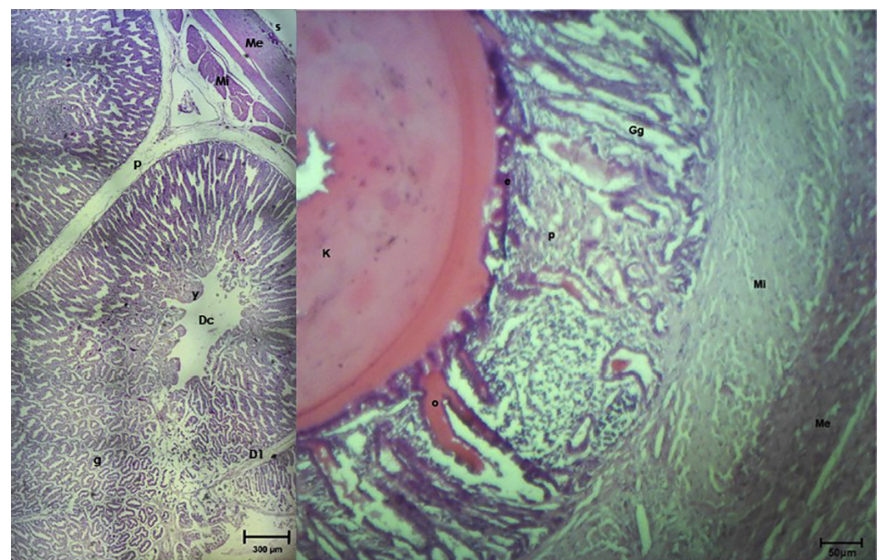

Fig.2. (2A) Proventrículo de frangos da linhagem Cobb e (2B) ventrículo. (2A) Serosa (s), Muscular externa (Me), Muscular interna (Mi), Glândulas mucosas (g), Papila gástrica (y), Ducto central (Dc), Ducto primário (D1). HE, obj.4x. (2B) Queratinóide $(\mathrm{K})$, Epitélio (e), Lâmina própria (p), Glândula gástrica (Gg), Muscular interna (Mi), Muscular externa (Me). HE, obj.10x.

Fig.3. Intestino delgado de frangos da linhagem Cobb. (3A) Duodeno. Vilo (v), Criptas de Lierberkuhn (CrL), Mucosa (m), Muscular interna (Mi), Muscular externa (Me), Serosa (s). HE, obj.4x. (3B) Jejuno Lúmen (L), Vilo (v), Células caliciformes (seta), Criptas de Lierberkuhn (CrL), Lâmina própria (p), Muscular da mucosa (mm), Muscular interna (Mi), Muscular externa (Me). HE, obj.10x. (3C) Íleo. Vilo (v), Cripta (Cr), Criptas de Lierberkuhn (CrL), Muscular interna (Mi), Muscular externa (Me), Serosa (s). HE, obj.10x.

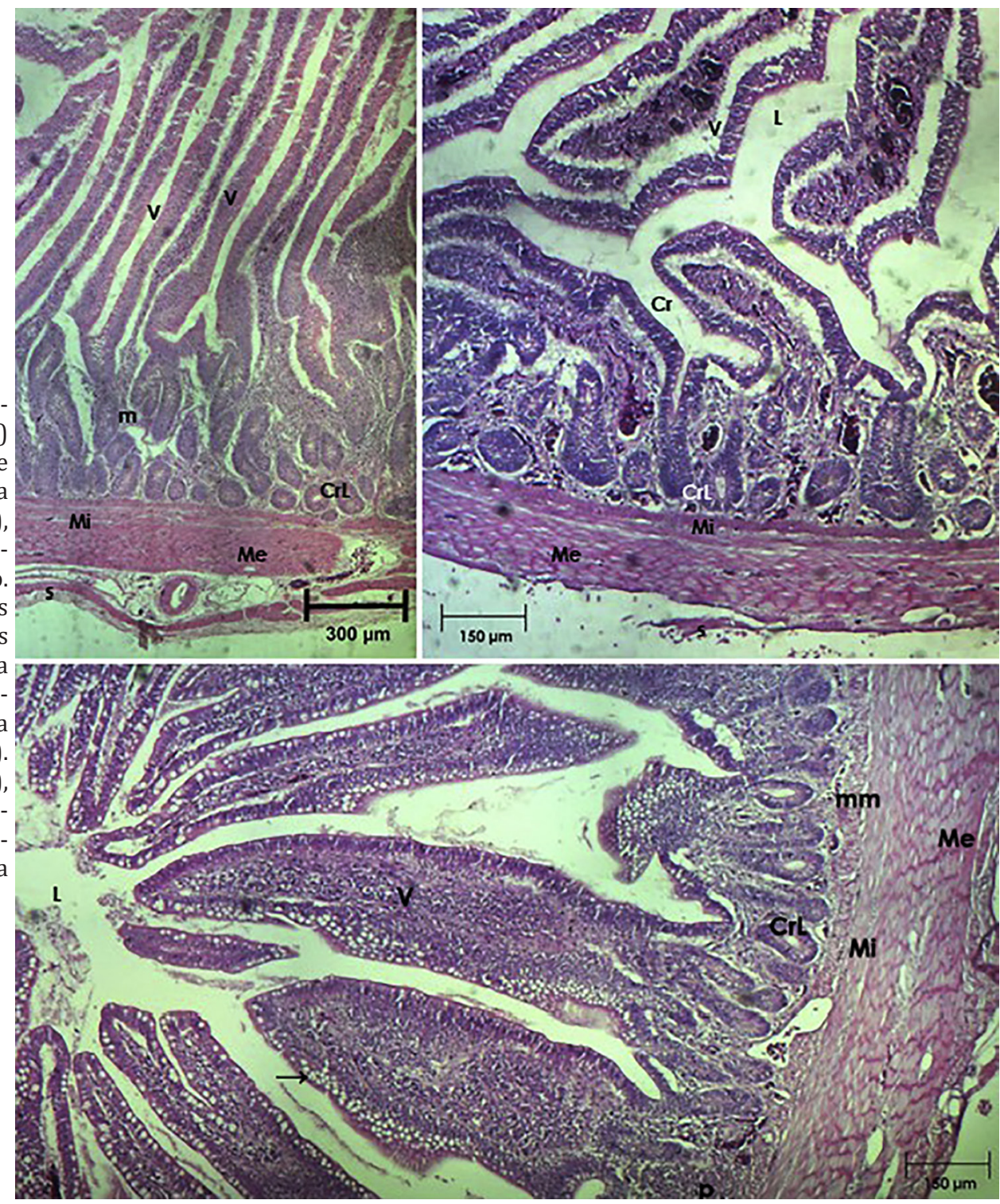


Já proventrículo é o estômago glandular das aves. Sua organização estrutural é similar à maioria dos órgãos do sistema digestório. Foi possível visualizar a túnica mucosa, essa é formada por vários lóbulos que correspondem às glândulas mucosas, no centro dessas é possível observar um ducto secundário e a secreção produzida pelas células secretoras, que apresentam um aspecto cuboide. A secreção da glândula mucosa é drenada pelo ducto secundário que se direciona para o ducto primário e desemboca no lúmen do órgão através de uma saliência da mucosa (papila). A mucosa das glândulas é formada por dobras e sulcos, e na mucosa encontram-se células glandulares (Fig.2A).

Além do estômago glandular, as aves possuem um estômago muscular ou mecânico, denominado ventrículo ou moela, o qual está situado entre o proventrículo e a primeira porção do intestino delgado, o duodeno. Na análise estrutural desse órgão visualizou-se túnica mucosa com presença de um conteúdo queratinóide em direção ao lúmen, produzido pelas glândulas gástricas contidas na lâmina própria, este mesmo conteúdo preenche os orifícios gástricos, que são os sulcos existentes entre as glândulas, estas têm conformação retilínea e são formadas por células

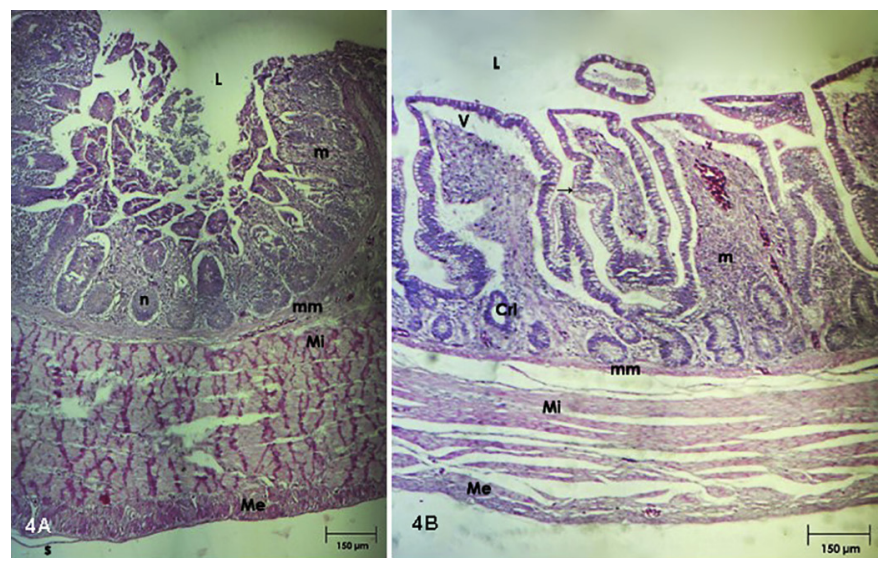

Fig.4. (4A) Ceco de frangos da linhagem Cobb e (4B) Cólon. (4A) Ceco. Lúmen (L), Mucosa (m), Nódulo linfático (n), Muscular da mucosa (mm), Muscular interna (Mi), Muscular externa (Me), Serosa (s). HE, obj.4x. (4B) Cólon. Lúmen (L), Vilo (v), Criptas de Lierberkühn (CrL), Mucosa (m), Muscular da mucosa (mm), Muscular interna (Mi), Muscular externa (Me). HE, objetiva 10x.

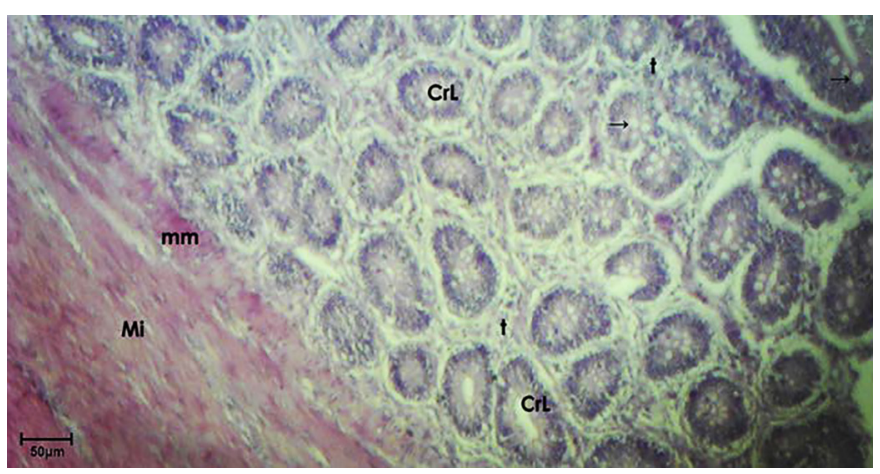

Fig.5. Duodeno de frangos da linhagem Cobb. Tecido linfático difuso (t), Criptas de Lierberkuhn (CrL), Células caliciformes (seta), Muscular da mucosa (mm), Muscular interna (Mi). HE, obj.20x. secretoras, semelhantes às caliciformes, possui uma túnica submucosa e uma túnica muscular externa bastante espessa (Fig.2B).

A estratigrafia do intestino delgado visualizada foi: túnica mucosa, lâmina própria, muscular da mucosa, muscular interna, muscular externa e serosa. A túnica mucosa é formada por várias vilosidades em direção ao lúmen intestinal, na lâmina própria observou-se uma densa camada de criptas de Lierberkühn (Fig.5), com maior destaque em espessura no segmento do duodeno, essas são ductos que se abrem entre a base do vilo e a muscular da mucosa. A diferença de uma porção intestinal para a outra é que as vilosidades se tornam mais delgadas e curtas em direção ao íleo (Fig.3A-C). No íleo destaca-se a grande quantidade de células caliciformes (Fig.6), também é possível observar que a profundidade das criptas diminui (Fig.3C). Os vilos estão presentes em toda extensão do intestino delgado e grosso, mas eles vão encurtando e tornando-os mais largos ao se aproximar do termino do tubo digestório. É visível na lâmina própria e na submucosa grande quantidade de tecido linfático, nodular e difuso ao longo de todo o intestino. Os cecos são apêndices de fungo cego, situado entre o intestino delgado e o intestino grosso, têm estruturação típica dos demais órgãos do intestino possuindo vilos na mucosa, porém em menor tamanho e mais largas, a lâmina própria e a submucosa são repletas de tecido linfático nodular e difuso (Fig.4A). Foi possível visualizar a tonsila cecal, que é caracterizada pelo acúmulo de nódulos linfáticos próximos ao orifício da base de cada ceco.

Quanto ao cólon, esse apresenta estrutura semelhante ao do intestino delgado, exceto por possuir vilos mais curtos e espessos (Fig.4B).

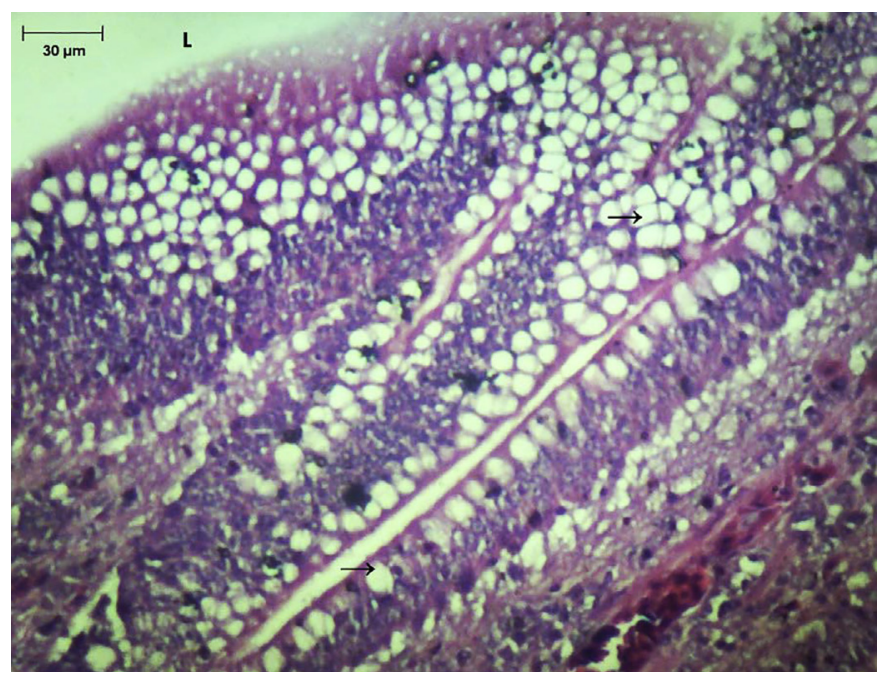

Fig.6. Vilos do íleo de frangos da linhagem Cobb, evidenciando numerosas suas células caliciformes (setas). Lúmen(L). HE, obj. 40x.

\section{DISCUSSÃO}

De modo geral, o tamanho e algumas características do trato gastrointestinal, podem sofrer influência da quantidade e do tipo de alimento consumido, um exemplo são as aves que consomem alimentos a base de fibra que tendem a apresentar sistema digestório mais longo (Bueno 2006). 
No entanto, existem aspectos relacionados à fisiologia do trato digestório que elucidam o maior desenvolvimento que determinados órgãos apresentam, em função do aumento de outros com os quais apresente relação fisiológica. Tendo em vista essas considerações, se torna possível compreender a ocorrência de correlações entre o comprimento de diferentes órgãos do tubo digestório e também em relação ao seu peso vivo dos animais analisados.

Ao analisar as correlações obtidas entre as variáveis, houve ocorrência de correlação entre comprimento do esôfago e do proventrículo, também obteve correlação significativa entre comprimento do esôfago e do ventrículo, ambas as correlações se explicam pelo fato do esôfago ser um tubo, que desempenha a função de lubrificação do bolo alimentar e de condução do mesmo, caso haja um aumento no trânsito de alimento ao longo do esôfago, consequentemente o proventrículo (estômago glandular) e o ventrículo (estômago muscular), tendem a aumentar suas dimensões para compensar a carga alimentar, fato esse que também pode justificar a ocorrência de correlação alta entre o comprimento do proventrículo e do ventrículo.

0 peso vivo do animal demonstrou correlação com o comprimento do duodeno, porção intestinal onde ainda há processos digestivos, pela ação do suco pancreático e da bile contendo suas enzimas digestivas e substâncias emulsificantes, através dos ductos pancreáticos e biliar, que se abrem no segmento ascendente do duodeno (Getty 1986); logo para esses animais adquirirem maior ganho de peso é necessário maior processo de metabolização dos nutrientes e uma maior absorção dos mesmos, com isso o duodeno tende a aumentar seu tamanho para melhor exercer sua função e aumentar sua superfície de absorção.

Há correlação positiva entre ceco direito e ceco esquerdo, por serem órgãos pares com desenvolvimento concomitante, atividade mutua.

O tamanho do duodeno apresentou correlação alta com ambos os cecos, contudo esta não foi significativa para o ceco esquerdo, provavelmente, por este ter apresentado uma amplitude relativamente grande. Este mesmo fator pode ter influenciado também a correlação entre o peso vivo e os cecos, uma vez que não foi significativo para 0 ceco esquerdo e foi significativo para o ceco direito.

Os resultados obtidos referentes às características estruturais microscópicas dos órgãos do tubo digestório das aves da linhagem Cobb $500^{\circledR}$, apresentaram semelhança com as demais aves domésticas da espécie Gallus domesticus, descritas por Banks (1998), Bacha \& Bacha (2003), avestruzes (Saviani 2013), Cyanoloxia brissonii cyanoides (Firmino 2013), S. flaveola braziliensis (Siqueira et al. 2013) e Rupornis magnirostris (Firmino et al. 2014).

No esôfago foi observado na muscular da mucosa tecido ondulado de músculo liso, em sentido longitudinal em direção ao lúmen, característica também observada por Banks (1998) e Bacha \& Bacha (2003) em Gallus domesticus, Illanes et al. (2006) em avestruzes adultos, Monteiro et al. (2009) em avestruzes jovens e em Rupornis magnirostris (Firmino et al. 2014). A mucosa desse órgão exibiu tecido epitelial pavimentoso estratificado queratinizado, característica essa citada por Banks (1998), que contradiz Bacha
\& Bacha (2003), que relata não haver queratinização nesse tecido em galinhas e Monteiro et al. (2009), que também não observou em avestruzes jovens. A lâmina própria apresentou várias glândulas mucosas, em concordância com o observado por Banks (1998) e Bacha \& Bacha (2003) em Gallus domesticus, diferentemente do que analisado por Rossi et al. (2006) em Rhynchotus rufescens (perdizes), que visualizou tais glândulas apenas na mucosa do esôfago.

No inglúvio não é comum à visualização das glândulas mucosas, porém uma amostra exibiu esta estrutura, devido a estas estarem na área de transição do esôfago com o inglúvio, segundo Banks (1998), essas glândulas estão ausentes no inglúvio das aves Galiformes e Columbiformes e presentes nas anseriformes.

A morfologia do proventrículo pode ser comparada com o das espécies de avaliadas por Banks (1998) e Bacha \& Bacha (2003), em Cyanoloxia brissonii cyanoides (Firmino 2013), semelhantes a S. flaveola braziliensis (Siqueira et al. 2013) e Rupornis magnirostris (Firmino et al. 2014), contudo, a nomenclatura do local de liberação da secreção das glândulas mucosas para o lumén do proventriculo denomina-se papila mucosa e ainda citam um ducto terciário coletor, que não foi visualizado no material analisado. Segundo Dyce et. al. (2010), essas papilas que se projetam para o lúmen apresentam um ducto excretor em cada papila, ducto este responsável pela liberação de suco gástrico, composto basicamente por ácido clorídrico e pepsina, para o início da digestão química. A estruturação do ventrículo não demonstrou diferença morfológica alguma em comparação as descrições realizadas por Banks (1998), Dellmann (1993), Bacha \& Bacha (2003) e Samuelson (2007) em outras aves domésticas.

Em relação ao intestino delgado as características exibidas também corroboram as observadas por Bacha \& Bacha (2003). As visualizações microscópicas são discrepantes das relatadas por Banks (1998), que cita não haver divisão histológica no intestino delgado. Algo digno de nota no intestino delgado foi a grande quantidade de células caliciformes presente no íleo, também observada por Bacha \& Bacha (2003) em galinhas, em avestruzes (Saviani 2013), Cyanoloxia brissonii cyanoides (Firmino, 2013), S. flaveola braziliensis (Siqueira et al. 2013) e Rupornis magnirostris (Firmino et al. 2014). As células caliciformes são secretoras de glicoproteínas (muco) que possuem o papel primário de proteger o epitélio intestinal da ação de enzimas digestivas e efeitos abrasivos da digestão, e outra função é servir como barreira contra patógenos (Boleli et al. 2002). Essa característica morfológica indica que a linhagem Cobb 500 pode apresentar resistência a patógenos, pois segundo Furlan et. al. (2004), os principais reservatórios de microrganismos patógenos em frangos são inglúvio, intestino e ceco.

Tanto os cecos quanto o colón apresentaram vilos na mucosa, discordando dos achados de Bezuidenhout \& Van Aswegen (1990) e Monteiro et. al. (2009) que descreveram em avestruzes adultos e jovens, respectivamente, ausência de vilos no colón e citam sua presença apenas no ceco, contudo, esses achados corroboram os descritos em outras aves domésticas por Banks (1998) e Bacha \& Bacha (2003). 


\section{CONCLUSÕES}

Conclui-se que a linhagem Cobb $500^{\circledR}$ demonstrou estratigrafia tecidual do tubo digestório, composta por quatro túnicas: mucosa, submucosa, muscular e serosa, com exceção do esôfago e inglúvio que ao invés de possuir túnica serosa possui a túnica adventícia.

No esôfago há presença de glândulas mucosa, e no inglúvio estas são ausentes. 0 proventrículo é estruturado por várias glândulas mucosas localizadas na túnica mucosa, que drenam suas secreções em ductos secundários e primários e ao ducto excretor em direção ao lúmen do órgão. 0 ventrículo possui um conteúdo queratinóide na túnica mucosa e glândulas gástricas na lâmina própria.

No intestino delgado é mais visível a presença de células caliciformes no íleo, porém também estão presentes no duodeno e no jejuno. Em ambos os intestinos delgado e grosso é visível à presença de vilos, que se tornam mais curtos e largos caudalmente ao tubo digestório, apresentam em seus segmentos a presença de tecido linfático difuso e nodular, sendo estes mais evidenciados no intestino grosso.

Agradecimentos.- À FAPEPI-Fundação de Amparo à Pesquisa do Estado do Piauí, pela concessão de bolsa de mestrado.

\section{REFERÊNCIAS}

Bacha W.J. \& Bacha L.M. 2003. Atlas Colorido de Histologia Veterinária. 2ª ed. Roca, São Paulo. 457p.

Banks W.J. 1998. Histologia Veterinária Aplicada. 2ª ed. Manole, São Paulo. 629p.

Bezuidenhout A.J. \& Van Aswegen G. 1990. A light microscopic and immunocytochemical study of the gastrointestinal tract of the ostrich (Struthio camelus L.). Onderstepoort J. Vet. Res. 57:37-48.

Bilgili S.F., Moran J.R. \& Acar N. 1992. Strain-cross response of male broilers to dietary lysine in the finisher feed: live performance furtherprocessing yields. Poult. Sci. 71(5):850-858.

Boleli I.C., Maiorka A. \& Macari M. 2002. Estrutura funcional do trato digestório, p.75-95. In: Ibid. (Eds), Fisiologia Aviária Aplicada a Frangos de Corte. FACTA - Fundação Apinco de Ciências e Tecnologia Avícolas, Campinas, SP.

Bueno F.L. 2006. Efeito da forma física, granulometria (DGM) e adição de óleo em dietas iniciais de frangos. Dissertação de Mestrado em Ciências Veterinárias, Universidade Federal do Paraná, Curitiba. 56p.

CFMV. 2012. Resolução n 1000 , de 11 de Maio de 2012. Dispõe sobre procedimentos e métodos de eutanásia em animais, e dá outras providências. Diário Oficial da União. Brasil. Disponível em <http://portal.cfmv. gov.br/portal/lei/index/id/326>. Acessado em 02 jul. 2014

Chen S., Cheng A.C., Wang M.S., Zhu D.K., Jia R.Y., Luo Q.H., Cui H.M., Zhou Y., Wang Y., Xu Z.W., Chen Z.L., Chen X.Y., Wang X.Y. 2010. Histopathology, immunohistochemistry, in situ apoptosis, and ultrastructure characterization of the digestive and lymphoid organs of new type gosling viral enteritis virus experimentally infected gosling. Poult. Sci., 89(4):668-680

Cobb Vantress Brasil. 2002. A Empresa. Disponível em <www.cobb.com. br> Acesso em ago. 2014.
Dellmann H.D. 1993. Histologia Veterinária. $2^{\text {a }}$ ed. Acribia, Zaragoza, Espanha. 398p.

Didio L.J.A. 1986. Variação anatômica, p.14-18. In: Getty R. (Ed.), Sisson/ Grossman Anatomia dos Animais Domésticos. Vol.1. 5a ed. Guanabara Koogan, Rio de Janeiro.

Dyce K.M., Sack W.O. \& Wensing C.J.G. 2010. Tratado de Anatomia Veterinária. 4⿳a ed. Elsevier, Rio de Janeiro, p.780-785.

Firmino M.O., Siqueira R.A.S., Luna A.C.L., Cavalcante T.A., Guerra M.V.S.F. \& Guerra R.R. 2013. Biometria externa, avaliação corpórea e morfologia do canal alimentar de azulão (Cyanoloxia brissonii cyanoides Lichtenstein, 1823). Revta. Agrotec. 34(1):1-8.

Firmino M.O., Siqueira R.A.S., Luna A.C.L., Cavalcante T.A. \& Guerra R.R. 2014. Caracterização biométrica externa, avaliação corpórea e caracterização histológica do trato gastrintestinal de gaviões-carijó (Rupornis magnirostris) apreendidos pelo CETAS/IBAMA na Paraíba. Biotemas 27(1):101-108.

Furlan R.L., Macari M. \& Luquetti B.C. 2004. Como avaliar os efeitos do uso de prebióticos, probióticos e flora de exclusão competitiva. 5 Simpósio Técnico de Incubação, Matrizes de Corte e Nutrição, Balneário Camboriú, SC, p.6-28.

Getty R. 1986. Anatomia dos Animais Domésticos. Vol.2. 5ae ed. Interamericana, Rio de Janeiro.

Hu C.H., Gu L.Y., Luan Z.S., Song J. \& Zhu K. 2012. Effects of montmorillonite-zinc oxide hybrid on performance, diarrhea, intestinal permeability and morphology of weanling pigs. Anim. Feed Sci. Technol. 177:108115.

Illanes J., Fertilio B., Chamblas M., Leyton V. \& Verdugo F. 2006. Descripción histológica de los diferentes segmentos del aparato digestivo de avestruz (Struthio camelus var. domesticus). Int. J. Morphol. 24:205-214.

King A.S. 1986. Variação anatômica, p.1677-1679. In: Getty R. (Ed.), Sisson/Grossman Anatomia dos Animais Domésticos. Vol.1. 5a ed. Guanabara Koogan, Rio de Janeiro.

Monteiro C.M.R., Souza N.T.M., Carvalho R.G. \& Souza W.M. 2009. Análise histológica do trato gastrintestinal de avestruzes jovens (Struthio camelus Linnaeus, 1758). Biotemas 22(3):149-155.

Rossi J.R., Baraldi-Artoni S.M., Oliveira D., Cruz C., Sagula A., Pacheco M.R. \& Araujo M.L. 2006. Morphology of oesophagus and crop of the partrigde Rhynchotus rufescens (Tiramidae). Acta Scient. Biol. Sci. 28(2):165-168.

Rostagno S.H. 2011. Tabelas Brasileiras para Aves e Suínos: composição de alimentos e exigências nutricionais. $3^{\underline{a}}$ ed. Universidade Federal de Viçosa, Viçosa, MG. 252p.

Samuelson D.A. 2007. Tratado de Histologia Veterinária. Elsevier, Rio de Janeiro. 527p.

Saviani G., Ponso R., Cogliati B., Araújo C.M.M., Santos J.M., Mariano A.N.B. \& Albuquerque R. 2013. Histologia do intestino do avestruz (Struthio camelus Linnaeus, 1758). Braz. J. Vet. Res. Anim. Sci. 50(4):265-269.

Siqueira R.A.S., Luna A.C.L., Cavalcanti T., Wagner P.G.C. \& Guerra R.R. 2013. Análise da condição corpórea, biometria externa e das vísceras do trato gastrointestinal de canários-da-terra, (S. flaveola braziliensis). Pesq. Vet. Bras. 33(3):379-383.

Viana F.A.B. 2007. Guia Terapêutico Veterinário. 2ª ed. Gráfica e Editora CEM, Lagoa Santa, MG.

Xia M.S., Hu C.H. \& Xu Z.R. 2004. Effects of copper bearing montmorillonite on growth performance, digestive enzyme activities, intestinal microflora and morphology of male broilers. Poult. Sci. 83:1868-1875. 